\title{
TRANSITION TIME PATHS FOR OVERLAPPING-GENERATIONS MODELS
}

\author{
John LAITNER* \\ University of Michigan, Ann Arbor, MI 48109, USA
}

Received October 1982, final version received January 1983

This paper examines the transition stages between steady states for an overlapping-generations growth model. Our procedure is based on eigenvalues and eigenvectors. For marginal parameter changes, we can generate exact 'multipliers' for the responses of state variables in each time period. Our solution technique is direct (rather than iterative), it yields an intermediate-stage test of stability, and it clearly reveals the need to interpret initial conditions carefully. We work several illustrative examples numerically.

\section{Introduction}

A number of recent papers use decentralized, overlapping-generations models to explore the consequences of permanent changes in exogenous variables. For example, Summers (1981) investigates the steady-state implications of reductions in taxes on interest incomes; Kotlikoff (1979) considers the long-run effect on national savings of a social security system [see also Samuelson (1975)]; Feldstein (1977) shows that a reduction in taxes on land rents can raise an economy's steady-state capital intensity; Laitner (1982a) shows that an increase in the prevalence of monopolistic pricing can lower an economy's long-run capital-to-labor ratio; and, Diamond (1965) shows that a larger national debt can adversely affect an economy's ability to accumulate physical capital. In each case, the analysis centers on long-term results. However, the short-run effects of permanent or temporary parameter changes in such models are also potentially interesting, both because transitions to steady states may take many years and because the intertemporal general equilibrium focus of overlapping-generations models may enable them to capture some aspects of reality which simpler frameworks miss.

If we are to study time intervals during which an economy moves between steady-state growth paths, we must be prepared to specify the manner in which private-sector agents form their expectations. In an overlapping-generations model with households living several periods, for instance, each family must predict income figures and interest rates over the remainder of its life span

*I owe thanks for the helpful comments of several referees of this journal. This research was supported in part by the National Science Foundation Grant No. SES-8106555. 
before being able to choose its present consumption and saving levels. A popular method of modeling anticipation formation is to assume perfect foresight for all agents (or, in the case of a stochastic framework, to assume that people's expectations are 'rational'). This approach has the virtue of not requiring a behavioral apparatus justifying anticipations in the private sector which do not make use of all potentially available information.

Auerbach, Kotlikoff and Skinner (1981) assume perfect foresight and study transition periods following tax changes. Their procedure is to specify arbitrarily a finite (but very long) time interval for the transition in question. They then guess values for the economy's state variables throughout the interval. Assuming people's expectations coincide with the guessed values, the authors can derive an actual time path for the state variables. They adjust their guesses until the latter exactly equal the derived values. A fixed point for the guessing process yields a perfect foresight equilibrium. Lipton, Poterba, Sacks and Summers (1982) also present a way of determining a solution. Discrete-time, perfect-foresight models usually can be rearranged into vector difference equations with split boundary conditions. Lipton et al. guess values for the missing initial conditions and simulate to the final state. ${ }^{1}$ The guesses are then modified until the simulated final state satisfies exogenous terminal boundary conditions. Because convergence of the algorithm may be difficult to obtain in practice, the authors propose dividing the total transition interval into segments - multiplying the dimensionality of the difference-equation system.

The purpose of this paper is to use eigenvalues and eigenvectors to study the transition phases between steady states for a perfect-foresight model resembling those surveyed in the first paragraph. Our approach does not require the a priori specification of termination dates for transitions, and it does not require an iterative solution procedure. It has the benefit of providing an interim-stage test for stability, which could save the effort of seeking a solution for a problem that does not have one. It also reveals clearly the interpretations we need to assign to various subsets of initial conditions.

After describing our methodology and solution concepts, we illustrate our analytical procedures with several examples - we examine a permanent change in the overall rate of technological progress and a permanent adjustment in tax rates on interest and labor income. Although the dimensionality of our problem is rather large, we had no difficulty in calculating tables of results. Section 4 discusses the sensitivity of our outcomes with respect to variations in selected parameters.

\section{Transition-period multipliers}

This section presents our method for deriving characterizations of dynamic adjustment paths. We begin with a description of the economic framework of

${ }^{1}$ Again we must arbitrarily specify a time interval for the complete transition phase. 
our analysis. As outlined briefly at the end of the section, there are a number of possible elaborations of the framework which would not fundamentally alter our computational difficulties.

\subsection{The economic framework}

We employ a slightly modified version of the life-cycle savings models of Diamond (1965) and Tobin (1967). We include an aggregate production function and a rudimentary government sector.

Our model keeps track of individual households. Each begins with a husband and wife, raises two children, and ends after not more than $N+1$ years. We normalize to a single representative family of each age at each time. Households are alike other than their starting dates: A family's date of birth determines the level of technological progress manifested in its 'effective' labor supply. There are no bequests or inheritances. Time is discrete. As in Diamond and Tobin, there is one output commodity produced in each period. The commodity is homogeneously divisible into investment, consumption, and government purchases. We normalize the good's current price to 1 in every period.

Consider the family $i \in\{0,1, \ldots, N\}$ years old at time $t$. We use the following notation: $c(i, t)$ is the family's current quantity of consumption; $\phi(c(i, t), i)$ is its age- $i$ utility; $l(i, t)$ is its (exogenously given) 'effective' labor supply; $r_{t}$ is the net-of-tax interest rate on savings carried from period $t-1$ to $t ; w_{t}$ is the current net-of-tax wage rate for 'effective' labor units; and $a(i, t)$ gives the family's beginning-of-period asset holdings at time $t$ - the assets having been carried over from period $t-1$. Tax rates reflect all tax revenues minus transfer payments from government other than retirement benefits. The latter receive special treatment because of their magnitude and timing: we increase the labor supply figures of older families to reflect retirement transfers (including social security) from government. Let $l(i, t)$ be the version of $l(i, t)$ augmented by such transfers.

Starting at age $i$ and time $t$, our family above chooses $c(j, t+j-i)$, for all $j=i, \ldots, N$, to solve

$$
\max _{c(\cdot)} \sum_{j=i}^{N} \phi(c(j, t+j-i), j),
$$

subject to

$$
\begin{aligned}
a(j+1, t+1+j-i)= & \left(1+r_{t+j-i}\right) \cdot a(j, t+j-i) \\
& +w_{t+j-i} \cdot i(j, t+j-i)-c(j, t+j-i) \\
& \text { for all } j=i, \ldots, N, \\
a(N, t+N-i) \geq 0, \quad & a(i, t) \text { given. }
\end{aligned}
$$


We assume that as a function of $c, \phi(c, j)$ is twice continuously differentiable, strictly concave, and strictly increasing. To rule out negative values for $c$, we let

$$
\lim _{c \downarrow 0} \partial u(c, j) / \partial c=\infty .
$$

If the rate of technological progress is not zero, we also need (for the existence of a steady state) preferences to be homothetic - which implies that $\phi(\cdot)$ must be a member of the Bergson (or isoelastic) class [see Katzner (1970, p. 31)]. Notice that because there are no inheritances,

$$
a(0, t)=0 \text { for all } t \text {. }
$$

We can easily relate household and aggregative variables. If $L_{t}$ is the aggregative 'effective' labor supply available for production at time $t$,

$$
L_{t}=\sum_{j=0}^{N} l(j, t) .
$$

We assume labor-augmenting technological progress at a fixed rate $\gamma$, and we assume government retirement benefits will be raised for successive generations at the same rate. Thus,

$$
\begin{aligned}
& l(j, t+1)=(1+\gamma) \cdot l(j, t), \\
& \bar{l}(j, t+1)=(1+\gamma) \cdot \bar{l}(j, t), \\
& L_{t+1}=(1+\gamma) \cdot L_{t} \text { for all } t .
\end{aligned}
$$

If $K_{t}$ is the aggregate physical capital stock at the start of period $t$, and if $D_{t}$ is the national debt,

$$
K_{t}+D_{t}=\sum_{j=0}^{N} a(j, t) .
$$

We assume physical capital used at time $t$ must have been manufactured (and financed) at time $t-1$ or before. Capital depreciates at a fixed proportional rate $\lambda$. Thus, if $I_{t}$ is time- $t$ gross (physical) investment,

$$
K_{t+1}=I_{t}+(1-\lambda) \cdot K_{t} .
$$

The time- $t$ capital-to-labor ratio is

$$
k_{t}=K_{t} / L_{t} .
$$


Let $Y$, be gross aggregate output at time $t$. We assume there is an aggregate production function $\psi(\cdot)$ with

$$
Y_{t}=\psi\left(K_{t}, L_{t}\right) .
$$

The production function is homogeneous of degree 1 , twice continuously differentiable, strictly increasing, and concave.

Our government sector is also streamlined. There is a proportional tax with rate $\tau_{w}$ on labor earnings and a proportional tax with rate $\tau_{r}$ for interest income. ${ }^{2}$ Competitive factor pricing implies

$$
\begin{aligned}
& w_{t}=\psi_{2}\left(K_{t}, L_{t}\right) \cdot\left(1-\tau_{w}\right), \\
& r_{t}=\left[\psi_{1}\left(K_{t}, L_{t}\right)-\lambda\right] \cdot\left(1-\tau_{r}\right) .
\end{aligned}
$$

The government can run a deficit. To allow long-run steady-state growth for the economy, as in Diamond (1965) we assume the deficit grows at rate $\gamma$. Thus, there is a constant $\delta$ such that for any $t$ the time- $t$ government deficit will be $\delta \cdot(1+\gamma)^{t}$. We have

$$
D_{t}=\delta \cdot(1+\gamma)^{t-1}+\delta \cdot(1+\gamma)^{t-2}+\cdots=\delta \cdot(1+\gamma)^{t} / \gamma .
$$

The government finances $D_{t}$ with one-period bonds issued at time $t-1$. We treat government spending as the residual category in the government budget constraint and assume the latter spending does not (directly) affect household utility-maximization calculations or the aggregate production function.

\subsection{The complete economy}

We now characterize the growth of the economy as a whole. As stated above, all agents have perfect foresight.

We first transform our variables to remove long-run trends. Let

$$
\begin{aligned}
& D_{t}^{*}=D_{t} /(1+\gamma)^{t}, \\
& K_{t}^{*}=K_{t} /(1+\gamma)^{t}, \\
& a^{*}(i, t)=a(i, t) /(1+\gamma)^{t}, \\
& L_{t}^{*}=L_{t} /(1+\gamma)^{t} .
\end{aligned}
$$

${ }^{2} \mathrm{At}$ the close of this section we comment on the feasibility of using a progressive tax structure. Section 3 experiments with several values for $\tau_{w^{\prime}}$ and $\tau_{r}$. 
If a superscript $T$ denotes a transpose, define

$$
x_{t}=\left(D_{t}^{*}, a^{*}(1, t), \ldots, a^{*}(N, t)\right)^{\mathrm{T}} \in R^{N+1} .
$$

[Recall eq. (5).] Let $p$ be the vector of parameters for the complete model including production and utility function coefficients, $\gamma, \tau_{w}, \tau_{r}$ and $\delta$.

We summarize our economic model as follows. For any vector $p$, given $x_{t-1}$ and anticipations about $k_{t}, \ldots, k_{t+N-1}$, households at time $t-1$ can use eqs. (8) and (12)-(13) to predict values of $r$ and $w$ for the present and over the remainder of their lives. Hence, the utility-maximization problem of eqs. (1)-(3) implies a function $F(\cdot, p): R^{N+1} \times R^{N} \rightarrow R^{N+1}$ with

$$
x_{t}=F\left(x_{t-1}, k_{t}, \ldots, k_{t+N-1}, p\right) .
$$

Because of the normalizations of eqs. (15)-(18), $F(\cdot)$ is time autonomous. Eq. (8) determines a second function $G(\cdot, p): R^{N+1} \rightarrow R^{1}$ with

$$
k_{t}=G\left(x_{r}, p\right) \text {. }
$$

All perfect foresight growth paths for our system must obey eqs. (20)-(21).

We can combine the last two equations. Let

$$
z_{t}=\left(z_{t}(1), \ldots, z_{t}(2 N)\right)^{\mathrm{T}}=\left(x_{t}^{T}, k_{t+1}, \ldots, k_{t+N-1}\right)^{\mathrm{T}} \in R^{2 N},
$$

and, if $F(\cdot)=\left(F^{1}(\cdot), \ldots, F^{N+1}(\cdot)\right)^{\mathrm{T}}$, let

$$
H\left(z_{t}, z_{t-1}, p\right)=\left(\eta_{1}, \ldots, \eta_{2 N}\right)^{\mathrm{T}} \in R^{2 N},
$$

with

$$
\begin{aligned}
& \eta_{j}=z_{t}(j)-F^{j}\left(z_{t-1}, z_{t}(2 N), p\right) \text { for all } j=1, \ldots, N+1, \\
& \eta_{j^{\prime}}=z_{t}\left(j^{\prime}\right)-z_{t-1}\left(j^{\prime}+1\right) \quad \text { for all } j^{\prime}=N+2, \ldots, 2 N-1, \\
& \eta_{2 N}=z_{t-1}(N+2)-G\left(F\left(z_{t-1}, z_{t}(2 N), p\right), p\right) .
\end{aligned}
$$

Then

$$
H\left(z_{t}, z_{t-1}, p\right)=0 \text { for all } t \geq 0
$$

is equivalent to having eqs. (20)-(21) hold for all $t \geq 0$.

\subsection{Local stability}

Suppose that for parameter vector $p^{*}$ our model has a steady-state solution $z^{*}=z^{*}\left(p^{*}\right) \in R^{2 N}$. In other words, suppose $z^{*}\left(p^{*}\right)$ obeys

$$
H\left(z^{*}\left(p^{*}\right), z^{*}\left(p^{*}\right), p^{*}\right)=0 .
$$


For future reference, let

$$
z^{*}\left(p^{*}\right)=\left(x^{*}\left(p^{*}\right)^{\mathrm{T}}, k^{*}\left(p^{*}\right), \ldots, k^{*}\left(p^{*}\right)\right)^{\mathrm{T}},
$$

and let

$$
\begin{aligned}
& H_{1}^{*}\left(p^{*}\right)=\partial H\left(z^{*}\left(p^{*}\right), z^{*}\left(p^{*}\right), p^{*}\right) / \partial z_{t}, \\
& H_{2}^{*}\left(p^{*}\right)=\partial H\left(z^{*}\left(p^{*}\right), z^{*}\left(p^{*}\right), p^{*}\right) / \partial z_{t-1} .
\end{aligned}
$$

We must digress briefly to consider the local asymptotic stability of $z^{*}$.

Assuming $H_{1}^{*}\left(p^{*}\right)$ is non-singular, and using the implicit function theorem, we can see that the local stability of $z^{*}$ must depend on the eigenvalues of

$$
M\left(p^{*}\right)=-\left[H_{1}^{*}\left(p^{*}\right)\right]^{-1} \cdot H_{2}^{*}\left(p^{*}\right)
$$

Notice that the matrix $M\left(p^{*}\right)$ is $2 N \times 2 N$.

Let our stability analysis begin at time $t=0$. Then we want to know if following a shock at time $0, z_{t}$ will converge to $z^{*}\left(p^{*}\right)$. Below we will think, for example, of a surprise (but permanent) parameter change from $p$ to $p^{*}$ occurring at $t=0$. Then at $t=0$, past events fix the national debt and family assets carried over from $t=-1$. So, the first $N+1$ components, $x_{0}^{\mathrm{T}}$, of $z_{0}$ must be exogenously given. In the terminology of Laitner (1982b) they are 'historical' initial conditions. In contrast, the remaining components of $z_{0}-k_{1}, \ldots, k_{N-1}-$ are 'non-historical'. They are not physically (directly) linked to the past. The surprise at time $t=0$ will have invalidated previous forecasts about $k_{1}, \ldots, k_{N-1}$, seemingly leaving us without initial values for them.

However, suppose $M\left(p^{*}\right)$ has one explosive eigenvalue for each non-historical element of $z_{0}$. Then if the economy is to converge to $z^{*}\left(p^{*}\right)$ after time 0 , there will only be one possible set of values for $k_{1}, \ldots, k_{N-1}$ - the set placing a zero loading on each eigenvalue with modulus greater than 1. If $M\left(p^{*}\right)$ has less than $N-1$ explosive eigenvalues, we will face an indeterminacy problem stemming from our lack of figures for $k_{1}, \ldots, k_{N-1}$. If $M\left(p^{*}\right)$ has more than $N-1$ unstable eigenvalues, we will not in general be able to reach $z^{*}\left(p^{*}\right)$. If $M\left(p^{*}\right)$ has exactly $N-1$ explosive roots, neither indeterminacy nor divergence need be a stumbling block [see Laitner 1981]. This is not to say that our model provides a mechanism insuring that agents will initialize (at $t=0$ ) their anticipations of $k_{1}, \ldots, k_{N-1}$ to insure convergence to $z^{*}\left(p^{*}\right)$ even if we do have the correct number of unstable characteristic roots. Nevertheless, we can argue that in the latter case nothing rules out either convergence or de- 
terminacy. In the context of a simpler model we might, in fact, be able to perform a global analysis which would exclude all paths except the convergent one [see, for example, Shell and Stiglitz (1967)].

Thus, from the standpoint of local asymptotic stability and determinacy we would like $M\left(p^{*}\right)$ to have $N+1$ eigenvalues of modulus less than 1 and $N-1$ with modulus exceeding 1 . This turns out to be the case in all of our numerical calculations in section 3 .

\subsection{Adjustment time paths}

Our focus of attention is the short-run adjustment time path of $z_{t}$ following a permanent change in an element $\theta$, say, $\theta=p(m)$, of parameter vector $p$. Let the new vector be $p^{*}$.

If for $z^{*}=z^{*}(p)$,

$$
H_{\theta}^{*}(p)=\partial H\left(z^{*}(p), z^{*}(p), p\right) / \partial p(m),
$$

a convenient way of presenting steady-state results about changes in $\theta$ is to solve for $\mathrm{d} z^{*}(p) / \mathrm{d} \theta \in R^{2 N}$ from

$$
: H_{1}^{*}(p) \cdot\left(\mathrm{d} z^{*} / \mathrm{d} \theta\right)+H_{2}^{*}(p) \cdot\left(\mathrm{d} z^{*} / \mathrm{d} \theta\right)+H_{\theta}^{*}(p)=0 \in R^{2 N} .
$$

The elements of $\mathrm{d} z^{*} / \mathrm{d} \theta$ correspond to what macroeconomists call 'multipliers': if we change $\theta$ by a small amount $\Delta \theta$, if we begin the analysis on a steady-state growth path for the original parameter values, and if the economy responds to the variation in $\theta$ by moving to a new steady state in the local vicinity of the former one, then $\left(\mathrm{d} z^{*} / \mathrm{d} \theta\right) . \Delta \theta$ approximates the long-run change in each element of $z^{*}=z^{*}(p)$.

We can derive corresponding short-run, or transition-phase, multipliers as follows. Given $p$ and $z_{0}$, eq. (24) determines $z_{t}$ for all $t \geq 1$. So, we can write

$$
z_{t}=\xi\left(t, p, z_{0}(p)\right) \text { for all } t \geq 1,
$$

where $z_{0}=z_{0}(p)$ because the last $N-1$ components of $z_{0}$ are non-historical (as discussed above). Let $\Delta \theta$ distinguish $p^{*}$ from $p$, and let

$$
\begin{aligned}
\mathrm{d} \xi\left(t, p, z_{0}(p)\right) / \mathrm{d} \theta= & \left(\partial \xi\left(t, p, z_{0}(p)\right) / \partial p(m)\right) \\
& +\left(\partial \xi\left(t, p, z_{0}(p)\right) / \partial z_{0}\right)\left(\partial z_{0}(p) / \partial p(m)\right) .
\end{aligned}
$$

Then

$$
\xi\left(t, p^{*}, z_{0}\left(p^{*}\right)\right)-\xi\left(t, p, z_{0}(p)\right) \cong\left(\mathrm{d} \xi\left(t, p, z_{0}(p)\right) / \mathrm{d} \theta\right) \cdot \Delta \theta .
$$


We study the case in which $p$ had been in force long enough to establish $z^{*}(p)$, but in which a change in $\theta$ (giving $p^{*}$ ) occurs at time $t=0$. Thus,

$$
\xi\left(t, p, z_{0}(p)\right)=z^{*}(p) \text { for all } t .
$$

Define

$$
\zeta_{f}=\mathrm{d} \xi\left(t, p, z_{0}(p)\right) / \mathrm{d} \theta .
$$

Then $\zeta_{t}$ for all $t \geq 0$ gives our sequence of short-term multipliers - see eq. (31). Replacing $z_{t}$ with $\xi\left(t, p, z_{0}(p)\right)$ in eq. (24), and differentiating,

$$
H_{1}^{*}(p) \cdot \zeta_{t}+H_{2}^{*}(p) \cdot \zeta_{t-1}+H_{\theta}^{*}(p)=0 .
$$

This equation enables us to analyze $\zeta_{t}$. We deal only with infinitesimal changes in $\Delta \theta$, for which eq. (31) is exact. ${ }^{3}$

Transform variables to

$$
\bar{\zeta}_{t}=\zeta_{t}-\left(\mathrm{d} z^{*}(p) / \mathrm{d} \theta\right)
$$

Then eqs. (29) and (34) imply

$$
H_{1}^{*}(p) \cdot \bar{\zeta}_{t}+H_{2}^{*}(p) \cdot \bar{\zeta}_{t-1}=0 .
$$

So, using eq. (27),

$$
\bar{\zeta}_{t}=M(p) \cdot \bar{\zeta}_{t-1}
$$

Consider our initial condition $\bar{\zeta}_{0}$. We know how to calculate $\mathrm{d} z^{*}(p) / \mathrm{d} \theta$ - see eq. (29). Because the elements of $x_{0}$ are 'historical', we have

$$
\mathrm{d} x_{0} / \mathrm{d} \theta=0 .
$$

We do not immediately know the remaining components of $\zeta_{0}$ $\mathrm{d} k_{1} / \mathrm{d} \theta, \ldots, \mathrm{d} k_{N-1} / \mathrm{d} \theta$ - we do not even know $k_{1}, \ldots, k_{N-1}$, as discussed above. However, if $z^{*}(p)$ is possibly to have the stability and determinacy properties of section $2.3, M(p)$ must have exactly $N-1$ eigenvalues with modulus greater than 1 . Unless we choose $\mathrm{d} k_{1} / \mathrm{d} \theta, \ldots, \mathrm{d} k_{N-1} / \mathrm{d} \theta$ to put zero

\footnotetext{
${ }^{3}$ To compute exact adjustments in $z_{1}$ all $t \geq 0$ following a medium or large change in $\theta$, we could turn to Lipton et al. (1982) - perhaps using our multipliers to obtain starting values for their iterative procedure. Although Laitner's (1981) proofs describe the construction of a precise solution, they only guarantee success when $\Delta \theta$ is small. An alternative approach is to check the magnitude of $\mathrm{d}^{2} z_{t} / \mathrm{d} \theta^{2}$ each $t \geq 0$ for clues of how much $\mathrm{d} z_{t} / \mathrm{d} \theta$ changes when $\theta$ does. See section 4 below - especially the fourth column of table 3 .
} 
loadings on the explosive roots, $\zeta$, will not converge to the vector of long-run multipliers $\mathrm{d} z^{*}(p) / \mathrm{d} \theta$ - in other words, $z_{t}$ will not converge to the new steady state. Thus, corresponding to our stability analysis, we have a way of choosing $\bar{\zeta}_{0}$.

Our steps are as follows. Let $E^{1}(i)$ be a square matrix with the stable eigenvalues of $M(p)$, each raised to the power $i$, along its principal diagonal and zeros elsewhere; let $E^{2}(i)$ be the same for the unstable roots; and, let $V=\left[V^{1} V^{2}\right]$ be the matrix of eigenvectors for $M(p)$, with $V^{j}$ containing the vectors corresponding to the eigenvalues in $E^{j}(1)$. Then

$$
\bar{\zeta}_{t}=V^{1} \cdot E^{1}(t) \cdot b_{1}+V^{2} \cdot E^{2}(t) \cdot b_{2},
$$

with $b_{1} \in R^{N+1}$ and $b_{2} \in R^{N-1}$ gives all solutions to eq. (36). For convergence [via eq. (38)] to a new steady state following a change in $\theta$, we will need $b_{2}=0 \in R^{N-1}$. Providing the first $N+1$ rows of $V^{1}$, say $V^{11}$, constitute a non-singular matrix, we can solve

$$
\left(\mathrm{d} x_{0} / \mathrm{d} \theta\right)-\left(\mathrm{d} x^{*}(p) / \mathrm{d} \theta\right)=-\mathrm{d} x^{*}(p) / \mathrm{d} \theta=V^{11} \cdot b_{1}
$$

for $b_{1}$. If the remaining rows of $V^{1}$ form $V^{21}$, the last $N-1$ elements of $\bar{\zeta}_{0}$ are then given by $V^{21} \cdot b_{1}$.

\subsection{Possible generalizations}

We have set up our economic framework, explained our basic difference equation system [see eq. (36)], and presented a method of obtaining adequate numbers of initial conditions - if we have exactly the correct number of eigenvalues for $M(p)$ with modulus less than 1. Before turning to numerical examples, we now comment briefly on several possible generalizations of our analysis.

The practical difficulty of implementing our derivation of short-run multipliers is the eigenvalue computation for $M(p)$. Elaborations of our economic system which do not substantially alter the dimensionality of $M(p)$ will, therefore, tend to be feasible to work with if our model is. As an example, suppose we make family labor-leisure choices endogenous, and suppose the new formulation's design permits a steady-state solution. Then we can repeat our analysis with only one new row and column for $M(p)$. If we could develop a sophisticated description of how the government adjusts tax rates, its spending, and its deficit in response to current fluctuations in the gross national product per capita, the dimensions of $M(p)$ would remain unchanged. The same would be true if we could replace our tax rates $\tau_{w}$ and $\tau_{r}$ with a twice continuously differentiable facsimile of a progressive tax system (having brackets which expand with the natural growth of the overall economy). On the 
other hand, if we try to introduce a new capital variable - such as a natural resource - the number of rows and columns in $M(p)$ would double.

\section{Examples}

This section presents two numerical examples which illustrate our procedure for studying time paths of adjustment. Both examples investigate permanent changes in exogenous variables - in one case, an alteration in the rate of labor-augmenting technological progress; in the other, a modification of the tax system. Numerous other computations are possible, of course.

\subsection{Parameter values}

First we must select functional forms for $\phi(\cdot)$ and $\psi(\cdot)$ and numerical values for all parameters.

We let $\psi(\cdot)$ be the constant elasticity function

$$
\psi(K, L)=\left[\alpha K^{-\rho}+(1-\alpha) L^{-\rho}\right]^{-1 / \rho} .
$$

The production elasticity of substitution is

$$
\sigma_{p}=1 /(1+\rho) \text {. }
$$

Following Tobin (1967), we sometimes set $\sigma_{p}=1$ - giving the Cobb-Douglas special case. In light of the time series estimates surveyed in Lucas (1969) and Nerlove (1967), we also try $\sigma_{p}=\frac{1}{2}$. National accounts data for 1981 suggest that labor's share of the gross national product is 0.65 . We adjust $\alpha$ to reach that share in every instance.

We construct an empirical measurement of the U.S. capital stock from Musgrave's (1982) constant-dollar fixed non-residential and residential private capital figures for 1981 plus national accounts data on business inventories during the same year. We also add the value of privately held land, assuming that the constant-dollar stock of land was the same in 1981 as in 1949, and using 1949 data from Goldsmith, Brady and Mendershausen (1965, table W3). Then using national accounts data on total depreciation in 1981, we determine $\lambda=0.06$.

We use Bergson utility functions for families. Households start with an 18 year old husband and wife. Each adult lives a maximum of 70 additional years - so that $N=70$. Following Tobin (1967), we compute the number of 'equivalent adults' per representative family of age $i \in\{0,1, \ldots, 70\}$ by summing the survival probabilities for males and females of age $18+i$ (taken from standard actuarial tables), 0.6 times the number of minor children, and 0.8 times the number of teenaged children. We assume a family's first child is born 
when the parents are 22 and its second when they are 24.8. Every child leaves home on his or her eighteenth birthday.

As in Tobin (1967), if $e_{i}$ is the number of equivalent adults for a family of age $i$,

$$
\phi(c, i)=\left(e_{i} / \beta\right) \cdot\left(c / e_{i}\right)^{\beta} \text { with } \beta<1 \text { and } \beta \neq 0,
$$

or

$$
e_{i} \cdot \ln \left(c / e_{i}\right)^{4}
$$

The (absolute value of the) inverse of the marginal utility of consumption with respect to consumption is

$$
\sigma_{c}=1 /(1-\beta),
$$

or, in the logarithmic case, $\sigma_{c}=1$. Tobin chooses $\sigma_{c}=1$. Other authors have used lower values. Weber (1970) generates estimates for $\sigma_{c}$ of $0.14,0.28$ and 0.41 . Weber (1975) derives figures of $\sigma_{c}=0.56$ and 0.75 . Given this backdrop, we try $\sigma_{c}=1$ and $\sigma_{c}=\frac{1}{2}$.

Our data on family labor supplies comes from U.S. Department of Health and Human Services (1981, tables 35-36). The most recent figures are for 1978. Fortunately, our results are invariant to the proportional labor supply changes over time which eq. (7) implies. We employ median labor earnings figures for different age and sex categories corrected for labor force participation and multiplied by survival probabilities. ${ }^{5}$ We then derive $i(i, 1978)$ for all $i=$ $0, \ldots, 70$ as outlined in section 1 , first making a proportional (upward) correction in $l(i, 1978)$, all $i$, to account for employers' contributions to governmentrun retirement programs (including social security). As in Summers (1981) and Kotlikoff (1979), we set the rate of labor-augmenting technological progress equal to $0.02 .^{6}$

National accounts data for 1981 on all federal, state, and local tax receipts less transfer payments other than retirement benefits implies an average tax rate of 0.28. Thus, some of our computations set $\tau_{r}=\tau_{w}=0.28$. As in Summers (1981) and Kotlikoff (1979), we try a higher tax, $\tau_{r}=0.40$, as well. ${ }^{7}$ For

\footnotetext{
${ }^{4}$ Notice that our notation is somewhat different from Tobin's (1967). In particular, his variable $c$ corresponds to our $c / e_{i}$.

${ }^{5}$ As in Tobin (1967), we implicitly assume the existence of zero transactions cost life insurance and annuity contracts. Several recent analyses of the importance of this assumption are Kotlikoff and Spivak (1981) and Davies (1981).

${ }^{6}$ This $\gamma$ is high for the very recent past [see Denison (1979)], but perhaps not for the long run. (At any rate, one of the potential uses of our model is to investigate the consequences of a reduction in $\gamma$.)

${ }^{7}$ See, for example, table 5 in Feldstein and Summers (1979).
} 
Table 1

Steady-state solutions.

\begin{tabular}{|c|c|c|c|c|c|}
\hline \multirow{3}{*}{$\frac{\text { Trial }}{1}$} & & & \multicolumn{3}{|c|}{ Steady-state values for } \\
\hline & \multicolumn{2}{|c|}{ Parameters $^{\mathrm{a}}$} & $K / Y$ & $k$ & $r$ \\
\hline & $\begin{array}{l}\tau_{w}=0.28, \\
\sigma_{c}=1,\end{array}$ & $\begin{array}{l}\tau_{r}=0.28 \\
\sigma_{p}=1\end{array}$ & 2.66 & 4.51 & 0.05 \\
\hline 2 & $\begin{array}{l}\tau_{w}=0.22, \\
\sigma_{c}=1\end{array}$ & $\begin{array}{l}\tau_{r}=0.40 \\
\sigma_{p}=1\end{array}$ & 2.48 & 4.06 & 0.05 \\
\hline 3 & $\begin{array}{l}\tau_{w^{\prime}}=0.22, \\
\sigma_{c}=1\end{array}$ & $\begin{array}{l}\tau_{r}=0.40 \\
\sigma_{p}=0.5\end{array}$ & 2.48 & 12.38 & 0.05 \\
\hline 4 & $\begin{aligned} \tau_{w^{\prime}} & =0.22 \\
\sigma_{c} & =0.5\end{aligned}$ & $\begin{array}{l}\tau_{r}=0.40 \\
\sigma_{p}=0.5\end{array}$ & 1.54 & 2.19 & 0.10 \\
\hline
\end{tabular}

'In every case, $\lambda=0.06, \gamma=0.02$, and labor's share $=0.65$.

consistency with our overall tax receipts figure, we set $\tau_{w}=0.22$ in the latter case. The size of the national debt held by private investors in 1981 and our growth rate of $\gamma=0.02$ imply a steady-state deficit-to-gross national product ratio of 0.0045 .

Table 1 presents numerically derived steady-state solutions for our model in four cases. As a comparison, our empirical capital stock figures (for 1981) imply a capital-to-output ratio of 1.91 .

\subsection{Multipliers}

Table 2 presents multiplier results, in elasticity form, for different parameter combinations. In each instance we developed closed-form expressions for all elements of $M(p)$ and $\mathrm{d} z^{*} / \mathrm{d} \theta$. We then solved for the eigenvalues of $M(p)$ numerically. We always found exactly $N+1=71$ eigenvalues with modulus less than 1 , and $N-1$ with modulus greater than 1 . So, as discussed at the close of section 1, neither indeterminacy nor lack of a convergent time path was ever a problem. In reading table 2 , notice that in every case the exogenous shock occurs at time $t=0$ and is a complete surprise. At the beginning of period 0 , the government deficits and private savings of previous periods fix the starting national debt and vector of family asset holdings. ${ }^{8}$ None of the variables in table 2 have long-run time trends.

Consider a rise in $\gamma$. In the context of a simple Solow (1956) model, if $s$ is the aggregate average propensity to consume, $\psi(\cdot)$ is the production function, and $k^{*}$ is a steady-state capital-to-labor ratio,

$$
s \cdot \psi\left(k^{*}, 1\right)=(\lambda+\gamma) \cdot k^{*} .
$$

\footnotetext{
${ }^{8}$ Recall our assumptions from section 2 - capital employed at time $t$ must have been built and financed at time $t-1$ or before.
} 
Table 2

Multipliers, in elasticity form, for permanent changes at time 0 in $\gamma$ and in tax rates."

\begin{tabular}{|c|c|c|c|c|c|c|c|c|}
\hline \multirow[b]{2}{*}{ Time } & \multicolumn{4}{|c|}{ Elasticity w.r.t. $\gamma$ for } & \multicolumn{4}{|c|}{ Elasticity w.r.t. $\tau_{w}$ for ${ }^{b}$} \\
\hline & $k$ & $r$ & $w^{c}$ & $\Delta K / Y^{d}$ & $k$ & $r$ & $w$ & $\Delta K / Y$ \\
\hline \multicolumn{9}{|c|}{ Trial 1 (with $\tau_{w^{\prime}}=0.28, \tau_{r}=0.28, \sigma_{c}=1$ and $\sigma_{p}=1$ ) } \\
\hline $\begin{array}{r}0 \\
1 \\
2 \\
3 \\
4 \\
5 \\
6 \\
7 \\
8 \\
9 \\
10 \\
11 \\
12 \\
15 \\
20 \\
50 \\
\infty\end{array}$ & $\begin{array}{r}0.000 \\
-0.026 \\
-0.050 \\
-0.073 \\
-0.095 \\
-0.115 \\
-0.134 \\
-0.152 \\
-0.169 \\
-0.184 \\
-0.199 \\
-0.213 \\
-0.226 \\
-0.259 \\
-0.300 \\
-0.355 \\
-0.346\end{array}$ & $\begin{array}{l}0.000 \\
0.031 \\
0.060 \\
0.088 \\
0.113 \\
0.138 \\
0.160 \\
0.182 \\
0.202 \\
0.221 \\
0.238 \\
0.254 \\
0.270 \\
0.309 \\
0.358 \\
0.425 \\
0.414\end{array}$ & $\begin{array}{r}0.000 \\
-0.009 \\
-0.018 \\
-0.026 \\
-0.033 \\
-0.040 \\
-0.047 \\
-0.053 \\
-0.059 \\
-0.064 \\
-0.070 \\
-0.074 \\
-0.079 \\
-0.090 \\
-0.105 \\
-0.124 \\
-0.121\end{array}$ & $\begin{array}{r}-0.320 \\
-0.261 \\
-0.204 \\
-0.150 \\
-0.097 \\
-0.047 \\
0.001 \\
0.047 \\
0.091 \\
0.133 \\
0.174 \\
0.212 \\
0.249 \\
0.349 \\
0.485 \\
0.780 \\
0.775\end{array}$ & $\begin{array}{l}0.000 \\
0.058 \\
0.114 \\
0.167 \\
0.218 \\
0.277 \\
0.313 \\
0.358 \\
0.401 \\
0.442 \\
0.481 \\
0.519 \\
0.554 \\
0.653 \\
0.789 \\
1.105 \\
1.097\end{array}$ & $\begin{array}{l}1.755 \\
1.686 \\
1.620 \\
1.556 \\
1.495 \\
1.438 \\
1.381 \\
1.327 \\
1.276 \\
1.227 \\
1.180 \\
1.135 \\
1.092 \\
0.975 \\
0.812 \\
0.434 \\
0.444\end{array}$ & $\begin{array}{l}-0.389 \\
-0.369 \\
-0.349 \\
-0.330 \\
-0.313 \\
-0.296 \\
-0.279 \\
-0.264 \\
-0.249 \\
-0.234 \\
-0.220 \\
-0.207 \\
-0.195 \\
-0.160 \\
-0.113 \\
-0.002 \\
-0.005\end{array}$ & $\begin{array}{l}2.957 \\
2.871 \\
2.789 \\
2.709 \\
2.632 \\
2.558 \\
2.486 \\
2.417 \\
2.351 \\
2.287 \\
2.225 \\
2.166 \\
2.108 \\
1.946 \\
1.711 \\
0.744 \\
0.713\end{array}$ \\
\hline \multicolumn{9}{|c|}{ Trial 2 (with $\tau_{w^{\prime}}=0.22, \tau_{r}=0.40, \sigma_{c}=1$ and $\sigma_{p}=1$ ) } \\
\hline $\begin{array}{r}0 \\
1 \\
2 \\
3 \\
4 \\
5 \\
6 \\
7 \\
8 \\
9 \\
10 \\
11 \\
12 \\
15 \\
20 \\
50 \\
\infty\end{array}$ & $\begin{array}{r}0.000 \\
-0.027 \\
-0.053 \\
-0.078 \\
-0.100 \\
-0.122 \\
-0.142 \\
-0.161 \\
-0.180 \\
-0.196 \\
-0.211 \\
-0.226 \\
-0.239 \\
-0.274 \\
-0.318 \\
-0.381 \\
-0.372\end{array}$ & $\begin{array}{l}0.000 \\
0.031 \\
0.060 \\
0.088 \\
0.114 \\
0.138 \\
0.161 \\
0.183 \\
0.203 \\
0.222 \\
0.239 \\
0.256 \\
0.271 \\
0.311 \\
0.360 \\
0.431 \\
0.421\end{array}$ & $\begin{array}{r}0.000 \\
-0.010 \\
-0.019 \\
-0.027 \\
-0.035 \\
-0.043 \\
-0.050 \\
-0.056 \\
-0.063 \\
-0.068 \\
-0.074 \\
-0.079 \\
-0.084 \\
-0.096 \\
-0.111 \\
-0.133 \\
-0.130\end{array}$ & $\begin{array}{r}-0.399 \\
-0.336 \\
-0.276 \\
-0.219 \\
-0.163 \\
-0.110 \\
-0.060 \\
-0.011 \\
0.036 \\
0.080 \\
0.122 \\
0.163 \\
0.202 \\
0.307 \\
0.449 \\
0.759 \\
0.758\end{array}$ & $\begin{array}{l}0.000 \\
0.056 \\
0.109 \\
0.160 \\
0.208 \\
0.255 \\
0.299 \\
0.342 \\
0.383 \\
0.422 \\
0.459 \\
0.494 \\
0.528 \\
0.621 \\
0.749 \\
1.042 \\
1.038\end{array}$ & $\begin{array}{l}1.527 \\
1.463 \\
1.403 \\
1.345 \\
1.290 \\
1.237 \\
1.187 \\
1.138 \\
1.092 \\
1.048 \\
1.006 \\
0.966 \\
0.927 \\
0.822 \\
0.678 \\
0.346 \\
0.350\end{array}$ & $\begin{array}{r}-0.282 \\
-0.263 \\
-0.244 \\
-0.226 \\
-0.209 \\
-0.193 \\
-0.177 \\
-0.162 \\
-0.148 \\
-0.134 \\
-0.121 \\
-0.109 \\
-0.097 \\
-0.065 \\
-0.020 \\
0.082 \\
0.081\end{array}$ & $\begin{array}{l}2.831 \\
2.747 \\
2.666 \\
2.587 \\
2.511 \\
2.438 \\
2.368 \\
2.300 \\
2.235 \\
2.172 \\
2.111 \\
2.053 \\
1.996 \\
1.837 \\
1.607 \\
0.710 \\
0.675\end{array}$ \\
\hline \multicolumn{9}{|c|}{ Trial 3 (with $\tau_{w}=0.22, \tau_{p}=0.40, \sigma_{c}=1$ and $\sigma_{p}=0.5$ ) (continued) } \\
\hline $\begin{array}{r}0 \\
1 \\
2 \\
3 \\
4 \\
5 \\
6 \\
7 \\
8 \\
9 \\
10 \\
11 \\
12\end{array}$ & $\begin{array}{r}0.000 \\
-0.019 \\
-0.036 \\
-0.052 \\
-0.067 \\
-0.081 \\
-0.094 \\
-0.106 \\
-0.117 \\
-0.128 \\
-0.137 \\
-0.146 \\
-0.154\end{array}$ & $\begin{array}{l}0.000 \\
0.042 \\
0.082 \\
0.118 \\
0.152 \\
0.184 \\
0.214 \\
0.241 \\
0.266 \\
0.289 \\
0.311 \\
0.330 \\
0.348\end{array}$ & $\begin{array}{r}0.000 \\
-0.013 \\
-0.025 \\
-0.036 \\
-0.047 \\
-0.057 \\
-0.066 \\
-0.074 \\
-0.082 \\
-0.089 \\
-0.096 \\
-0.102 \\
-0.108\end{array}$ & $\begin{array}{l}0.048 \\
0.100 \\
0.151 \\
0.198 \\
0.243 \\
0.286 \\
0.326 \\
0.364 \\
0.400 \\
0.434 \\
0.466 \\
0.496 \\
0.525\end{array}$ & $\begin{array}{l}0.000 \\
0.028 \\
0.054 \\
0.078 \\
0.102 \\
0.124 \\
0.145 \\
0.165 \\
0.183 \\
0.201 \\
0.218 \\
0.234 \\
0.249\end{array}$ & $\begin{array}{l}1.181 \\
1.118 \\
1.059 \\
1.003 \\
0.950 \\
0.900 \\
0.853 \\
0.808 \\
0.765 \\
0.725 \\
0.687 \\
0.651 \\
0.617\end{array}$ & $\begin{array}{l}-0.282 \\
-0.263 \\
-0.244 \\
-0.227 \\
-0.211 \\
-0.195 \\
-0.181 \\
-0.167 \\
-0.154 \\
-0.141 \\
-0.130 \\
-0.118 \\
-0.108\end{array}$ & $\begin{array}{l}1.404 \\
1.348 \\
1.294 \\
1.243 \\
1.195 \\
1.149 \\
1.105 \\
1.064 \\
1.025 \\
0.988 \\
0.953 \\
0.920 \\
0.888\end{array}$ \\
\hline
\end{tabular}


Table 2 (continued)

\begin{tabular}{|c|c|c|c|c|c|c|c|c|}
\hline \multirow[b]{2}{*}{ Time } & \multicolumn{4}{|c|}{ Elasticity w.r.t. $\gamma$ for } & \multicolumn{4}{|c|}{ Elasticity w.r.t. $\tau_{w}$ for ${ }^{b}$} \\
\hline & $k$ & $r$ & $w^{\mathrm{c}}$ & $\Delta K / Y^{\mathrm{d}}$ & $k$ & $r$ & $w$ & $\Delta K / Y$ \\
\hline \multicolumn{9}{|c|}{ Trial 3 (with $\tau_{w}=0.22, \tau_{r}=0.40, \sigma_{c}=1$ and $\sigma_{p}=0.5$ ) } \\
\hline $\begin{array}{l}15 \\
20 \\
50 \\
\infty\end{array}$ & $\begin{array}{l}-0.174 \\
-0.197 \\
-0.220 \\
-0.215\end{array}$ & $\begin{array}{l}0.394 \\
0.447 \\
0.498 \\
0.487\end{array}$ & $\begin{array}{l}-0.122 \\
-0.138 \\
-0.154 \\
-0.151\end{array}$ & $\begin{array}{l}0.601 \\
0.699 \\
0.865 \\
0.860\end{array}$ & $\begin{array}{l}0.289 \\
0.343 \\
0.456 \\
0.454\end{array}$ & $\begin{array}{l}0.525 \\
0.403 \\
0.148 \\
0.153\end{array}$ & $\begin{array}{r}-0.029 \\
-0.042 \\
0.037 \\
0.036\end{array}$ & $\begin{array}{l}0.802 \\
0.685 \\
0.299 \\
0.295\end{array}$ \\
\hline \multicolumn{9}{|c|}{ Trial 4 (with $\tau_{w}=0.22, \tau_{r}=0.40, \sigma_{c}=0.5$ and $\sigma_{p}=0.5$ ) } \\
\hline $\begin{array}{r}0 \\
1 \\
2 \\
3 \\
4 \\
5 \\
6 \\
7 \\
8 \\
9 \\
10 \\
11 \\
12 \\
15 \\
20 \\
50 \\
\infty\end{array}$ & $\begin{array}{l}0.000 \\
-0.024 \\
-0.047 \\
-0.070 \\
-0.091 \\
-0.112 \\
-0.132 \\
-0.151 \\
-0.169 \\
-0.186 \\
-0.202 \\
-0.218 \\
-0.233 \\
-0.272 \\
-0.322 \\
-0.369 \\
-0.364\end{array}$ & $\begin{array}{l}0.000 \\
0.043 \\
0.084 \\
0.123 \\
0.161 \\
0.198 \\
0.233 \\
0.266 \\
0.299 \\
0.329 \\
0.358 \\
0.385 \\
0.411 \\
0.481 \\
0.569 \\
0.653 \\
0.644\end{array}$ & $\begin{array}{r}0.000 \\
-0.017 \\
-0.033 \\
-0.049 \\
-0.064 \\
-0.078 \\
-0.092 \\
-0.106 \\
-0.118 \\
-0.130 \\
-0.142 \\
-0.153 \\
-0.162 \\
-0.190 \\
-0.225 \\
-0.258 \\
-0.255\end{array}$ & $\begin{array}{r}-0.228 \\
-0.201 \\
-0.173 \\
-0.144 \\
-0.114 \\
-0.083 \\
-0.052 \\
-0.021 \\
0.011 \\
0.044 \\
0.076 \\
0.109 \\
0.142 \\
0.239 \\
0.395 \\
0.795 \\
0.763\end{array}$ & $\begin{array}{l}0.000 \\
0.011 \\
0.022 \\
0.033 \\
0.045 \\
0.057 \\
0.069 \\
0.082 \\
0.095 \\
0.108 \\
0.121 \\
0.134 \\
0.148 \\
0.189 \\
0.257 \\
0.489 \\
0.478\end{array}$ & $\begin{array}{l}0.991 \\
0.973 \\
0.953 \\
0.933 \\
0.912 \\
0.891 \\
0.869 \\
0.847 \\
0.824 \\
0.801 \\
0.778 \\
0.754 \\
0.730 \\
0.657 \\
0.537 \\
0.127 \\
0.146\end{array}$ & $\begin{array}{l}-0.282 \\
-0.275 \\
-0.267 \\
-0.259 \\
-0.251 \\
-0.242 \\
-0.234 \\
-0.225 \\
-0.216 \\
-0.207 \\
-0.197 \\
-0.188 \\
-0.178 \\
-0.150 \\
-0.102 \\
0.060 \\
0.052\end{array}$ & $\begin{array}{l}0.544 \\
0.570 \\
0.596 \\
0.620 \\
0.643 \\
0.666 \\
0.688 \\
0.708 \\
0.728 \\
0.746 \\
0.762 \\
0.777 \\
0.791 \\
0.821 \\
0.844 \\
0.319 \\
0.311\end{array}$ \\
\hline
\end{tabular}

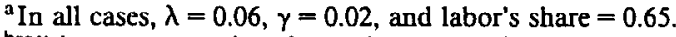

${ }^{b} W$ ith a compensating change in $\tau_{r}$ - see the text.

$c^{c} w$ is the gross wage per 'effective' labor unit.

$\mathrm{d} \Delta K / Y$ is the net investment-to-GNP ratio.

If $s$ is a constant and $\sigma_{p}=1, \mathrm{~d} \ln \left(k^{*}\right) / \mathrm{d} \ln (\gamma)$ would equal $[1 /(\alpha-1)]$. $[\gamma /(\lambda+\gamma)]$, or, with our parameters, about -0.38 .

In our model, $s$ is not a constant, however, and we have a government sector. Concentrating on $s$, if $\gamma$ increases, we might expect the following long-run effects. First, provided young families tend to save and retired families to dissave, an increase in $\gamma$ will tend to raise the steady-state magnitude of the former figures relative to the latter - causing $s$ to rise. Second, with Bergson preferences, a family's consumption in youth will tend to depend positively on the present value of its future labor earnings [see the equations in Tobin (1967) and Summers (1981)]. Hence, a rise in $\gamma$ will tend to increase youthful consumption at the expense of saving. Third, if $k^{*}$ falls, the resulting rise in interest rates will reduce the present value of each family's future labor earnings, tending to increase saving early in life [see table 1 in Summers (1981), for instance]. On the other hand, at least in the case of $\sigma_{p}=1$, if family preferences are homothetic, a permanent change in $w$ will have no influence on $s$. 
If $s$ tends to rise with $\gamma$ in the long run, eq. (44) shows $\left|\mathrm{d} \ln \left(k^{*}\right) / \mathrm{d} \ln (\gamma)\right|$ should be reduced. For most of the trials in table 2, however, our $\mathrm{d} \ln \left(k^{*}\right) / \mathrm{d} \ln (\gamma)$ figures agree fairly closely with -0.38 . Thus, the various long-run effects on $s$ appear roughly to cancel one another out.

In the very short run, our first and third long-run effects may not operate. The second will. In fact, a rise in $\gamma$ at time 0 will create a one-time-only (at $t=0$ ) windfall gain in lifetime earnings for all non-retired families. Thus, there may be a substantial temporary decline in $s$, which would tend to speed the convergence of $k_{t}$ down to $k^{*}$. The decline in $s$ shows up in table 2 in the form of low investment spending as a fraction of output for as many as seven periods. Eventually the first and third long-run effects of $\gamma$ on $s$ should come into play.

Table 2 reveals half-lives of 7-9years for the convergence of $k_{t}$ following a change in $\gamma$. In contrast to simpler growth models, these are, if anything, surprisingly short - see, for instance, Sato (1963). The responses of saving described in the preceding paragraph provide an explanation. If $s$ is fixed in eq. (44) and $\sigma_{p}=1$, our parameter values for $\lambda, \gamma$ and $\alpha$ imply a half-life for the convergence of $k_{t}$ on the order of 13-14 years. ${ }^{9}$

Our second example considers a permanent marginal increase in $\tau_{w}$. The change begins at time $t=0$. It is accompanied by a one-time-only adjustment in $\tau_{r}$ of: sufficient magnitude to keep steady-state tax receipts at previous levels. ${ }^{10}$

An increase in $\tau_{w}$ coupled with a decrease in $\tau_{r}$ will raise the net interest rate at time 0 and lower net wages. Our analysis above indicates that, at least if $\sigma_{p}=1$, in the long run this may tend to raise the aggregate average propensity to save and, hence, the steady-state capital-to-labor ratio. Table 2 and Summers' (1981) results bear this out. Since short-run adjustments in this case depend entirely on induced factor price changes, we should not be too surprised to find longer half-lives to convergence for $k_{t}$ than on the left-hand side of table 2. In fact, the tax change half-lives for $k_{t}$ fall between 10 and 20 years.

Our basic equations [see eq. (36)] show that for one $p$, studies of changes in $\gamma$ and in taxes employ the same matrix $M(p)$ - only the vector $\mathrm{d} z^{*} / \mathrm{d} \theta$ differs. Thus, if we derive entries for $M(p)$ and complete our most demanding computation - finding the eigenvalues and eigenvectors for $M(p)$, which is $140 \times 140$ - once, we can use the results to determine both growth-rate and tax-change multipliers. For each parameter vector $p$, the computation time (with double precision variables) for a single trial in table 2 on an Amdaht 5860 computer was $35-40$ seconds. As stated, we derived closed-form func-

\footnotetext{
${ }^{9}$ This half-life is based on a linearization of Solow's (1956) equation of motion about its steady-state value of $k$. With $\sigma_{p}=1$, the half-life to convergence is then $\ln (0.5) /[(\lambda+\gamma)(\alpha-1)]$.

${ }^{10} \mathrm{An}$ aiternative would be to adjust $\tau_{r}$ period-by-period to hold total tax receipts [normalized by $(1+\gamma)^{\prime}$ ] constant during all transition phases as well as steady states. That would require a parameterization in which normalized total tax revenues and $\tau_{w}$ (instead of $\tau_{r}$ and $\tau_{w}$ ) were elements of $p$.
} 
Table 3

Sensitivity analysis with respect to selected parameters (assuming $\lambda=0.06, \gamma=0.02, \alpha=0.35$, $\left.\tau_{w}=0.28, \tau_{r}=0.28, \sigma_{c}=1, \sigma_{p}=1\right)$.

\begin{tabular}{|c|c|c|c|c|c|c|c|c|}
\hline \multirow[b]{2}{*}{ Time } & \multicolumn{4}{|c|}{$\begin{array}{l}\text { Elasticity of growth } \\
\text { rate multiplier for } k \text { w.r.t. }\end{array}$} & \multicolumn{4}{|c|}{$\begin{array}{l}\text { Elasticity of tax } \\
\text { rate multiplier for } k \text { w.r.t. }\end{array}$} \\
\hline & $\sigma_{c}$ & $\sigma_{p}$ & $\gamma$ & $\lambda$ & $\sigma_{c}$ & $\sigma_{p}$ & $\gamma$ & $\lambda$ \\
\hline 0 & 0.000 & 0.000 & 0.000 & 0.000 & 0.000 & 0.000 & 0.000 & 0.000 \\
\hline 1 & -0.405 & 0.460 & 0.986 & 0.010 & 0.692 & 0.771 & 0.407 & 0.594 \\
\hline 2 & -0.423 & 0.469 & 0.980 & -0.004 & 0.663 & 0.780 & 0.400 & 0.579 \\
\hline 3 & -0.441 & 0.477 & 0.974 & -0.017 & 0.635 & 0.788 & 0.393 & 0.564 \\
\hline 4 & -0.458 & 0.486 & 0.969 & -0.030 & 0.608 & 0.796 & 0.387 & 0.550 \\
\hline 5 & -0.475 & 0.494 & 0.964 & -0.043 & 0.582 & 0.804 & 0.380 & 0.535 \\
\hline 6 & -0.491 & 0.502 & 0.959 & -0.056 & 0.555 & 0.811 & 0.373 & 0.521 \\
\hline 7 & -0.507 & 0.510 & 0.954 & -0.068 & 0.530 & 0.819 & 0.367 & 0.508 \\
\hline 8 & -0.522 & 0.519 & 0.949 & -0.080 & 0.505 & 0.826 & 0.360 & 0.494 \\
\hline 9 & -0.537 & 0.526 & 0.934 & -0.092 & 0.480 & 0.833 & 0.354 & 0.481 \\
\hline 10 & -0.551 & 0.534 & 0.939 & -0.104 & 0.457 & 0.840 & 0.348 & 0.468 \\
\hline 11 & -0.565 & 0.541 & 0.934 & -0.116 & 0.433 & 0.847 & 0.342 & 0.455 \\
\hline 12 & -0.578 & 0.549 & 0.930 & -0.128 & 0.411 & 0.853 & 0.336 & 0.442 \\
\hline 15 & -0.615 & 0.571 & 0.917 & -0.160 & 0.346 & 0.871 & 0.318 & 0.406 \\
\hline 20 & -0.667 & 0.605 & 0.898 & -0.211 & 0.250 & 0.898 & 0.292 & 0.350 \\
\hline 50 & -0.780 & 0.727 & 0.852 & -0.377 & -0.033 & 0.983 & 0.193 & 0.146 \\
\hline$\infty$ & -0.809 & 0.722 & 0.925 & -0.388 & 0.000 & 1.003 & 0.182 & 0.126 \\
\hline
\end{tabular}

tions for the elements of $M(p)$ and $\mathrm{d} z^{*} / \mathrm{d} \theta$. The eigenvalue calculations used a standardized algorithm. ${ }^{11}$

The majority of the eigenvalues with moduli less than 1 in each case were complex. Table 2 shows, however, that cycles seem to play a rather minor role in the evolution of multipliers for aggregative variables. As an example, the minimum and maximum cyclic periods for stable characteristic roots were 2 and 52 years in our first trial.

\section{Sensitivity analysis}

The parameters we use in our examples originate from a variety of sources and have magnitudes which are by no means certain. We should, therefore, be curious about the extent to which the outcomes in section 3 vary if the parameters take different values. One approach is to repeat our analysis for a number of vectors $p$. Table 2 provides some results along these lines. Another way of proceeding is to calculate the elasticities of the multipliers in table 2 with respect to selected parameters. We pursue the latter tack here.

Table 3 presents examples of the new elasticities. We generated the table's entries by changing a given element of the parameter vector $p$, say, $\theta^{\prime}$, by 1

${ }^{11}$ The algorithm is a public Fortran subroutine on the University of Michigan computer system. It is briefly described in paragraph 3.2 .019 of Harding (1979), and thoroughly discussed in Smith, Boyle, Dongarra, Garbow, Ikebe, Klema and Molar (1976). According to Mr. Harding, the algorithm is useful for matrices up to 150 by 150 . 
percent; recalculating all multipliers in table 2 numerically; and then deriving the percentage variation for each multiplier. Although in principle we could have developed similar results using closed-form expressions, differentiating eq. (36) with respect to $\theta^{\prime}$ yields a very cumbersome array of terms.

The figures in table 3 illustrate the sensitivity, at least locally, of our multipliers to changes in $\sigma_{c}, \sigma_{p}, \gamma$ and $\lambda$. Only one of the entries exceeds 1 . A 1 percent reduction in $\gamma$, for example, changes the period-1 growth-rate multiplier in table 2 from -0.0259 to -0.0256 - in other words, by about 1 percent. For the period-1 tax-rate multiplier, the change is from 0.0579 to 0.0577 . Such outcomes should give us some confidence that if our parameter choices are fairly realistic, the same will tend to follow for the results in table 2.

\section{Conclusion}

We have presented a method for studying the transition phases of a well-known model which is usually only used for analyzing steady states. The method is based on eigenvalues and eigenvectors. At an intermediate stage we can count the number of eigenvalues of modulus less than 1 to be sure that we have enough to proceed. Our solution does not rely on iterative steps. Our results take a convenient and familiar form and are exact for marginal parameter variations.

The illustrative numerical examples in section 3 generally reveal half-lives for convergence to a new steady state on the order of a decade - at least in the case of aggregative multipliers. With perfect foresight, even the immediate response of investment to permanent changes in taxes or in the rate of technological progress is quite noticeable in most cases. Although our transition time paths are cyclic, in the case of aggregative variables the cycles are very gentle.

\section{References}

Auerbach, A.J., L.J. Kotlikoff and J. Skinner, 1981, The efficiency gains from dynamic tax reform, Discussion paper no. 870 (Harvard University, Cambridge, MA).

Davies, J.B., 1981, Uncertain lifetime, consumption and dissaving in retirement, Journal of Political Economy 89, 561-577.

Denison, E.F., 1979, Accounting for slower growth: The United States in the 1970s (Brookings Institute, Washington, DC).

Diamond, P.A., 1965, National debt in a neoclassical growth model, American Economic Review $55,1126-1150$.

Feldstein, M., 1977, The surprising incidence of a tax on pure rent: A new answer to an old question, Journal of Political Economy 85, 349-360.

Feldstein, M. and L. Summers, 1979, Inflation and the taxation of capital income in the corporate sector, National Tax Journal 32, 445-470.

Goldsmith, R.W., D.S. Brady and H. Mendershausen, 1965, A study of saving in the United States, Vol. III (Princeton University Press, Princeton, NJ).

Harding, L.J., 1979, Numerical analysis and applications software abstracts, Computing Center memo no. 407 (University. of Michigan, Ann Arbor, MI). 
Katzner, D., 1970, Static demand theory (Macmillan, New York).

Kotlikof, L.J., 1979, Social security and equilibrium capital intensity, Quarterly Journal of Economics 93, 233-254.

Kotlikoff, L.J. and A. Spivak, 1981, The family as an incomplete annuities market, Journal of Political Economy 89, 372-391.

Laitner, J.P., 1981, The stability of stcady states in perfect foresight models, Econometrica 49, $319-334$.

Laitner, J.P., 1982a, Monopoly and long-run capital accumulation, Bell Journal of Economics 13, $143-157$.

Laitner, J.P., 1982b, The definition of stability in models with perfect foresight, Journal of Economic Theory 28, 347-353.

Lipton, D., J. Poterba, J. Sacks and L. Summers, 1982, Multiple shooting in rational expectations models, Econometrica 50, 1329-1334.

Lucas, R.E., 1969, Labor-capital substitution in U.S. manufacturing, in: A.C. Harberger and M.J Bailey, eds., The taxation of income from capital (Brookings Institution, Washington, DC) 223-274.

Musgrave, J., 1982, Fixed reproducible tangible wealth in the United States, Survey of Current Business 62, 33-36.

Nerlove, M., 1967, Recent empirical studies of the CES and related production functions, in: M. Brown, ed., The theory and empirical analysis of production (Columbia University Press, New York) 55-122.

Samuelson, P.A.. 1975, Optimal social security in a life-cycle growth model, International Economic Review 16, 539-544.

Sato, R., 1963, Fiscal policy in a neo-classical growth model: An analysis of time required for equilibrating adjustment, Review of Economic Studies 30, 16-23.

Shell, K. and J.E. Stiglitz, 1967, The allocation of investment in a dynamic economy, Quarterly Journal of Economics 81, 592-609.

Smith, B.T., J.M. Boyle, J.J. Dongarra, B.S. Garbow, Y. Ikebe, V.C. Klema and C.B. Molar, 1976, Matrix eigensystem routines - EISPACK guide (Springer-Verlag, Berlin).

Solow, R.M., 1956, A contribution to the theory of economic growth, Quarterly Journal of Economics 70, 65-94.

Summers, L.H., 1981, Capital taxation and accumulation in a life cycle growth model, American Economic Review 71, 533-544.

Tobin, J. 1967, Life cycle saving and balanced growth, in: W. Fellner, ed., Ten economic essays in the tradition of Irving Fisher (Wiley, New York) 231-256.

U.S. Department of Health and Human Services, Social Security Administration, 1981, Social security bulletin, Annual statistical supplement, 1981 (U.S. Government Printing Office, Washington, DC).

Weber, W.E., 1970, The cffect of interest rates on aggregate consumption, American Economic Review 60, 591-600.

Weber, W.E., 1975, Interest rates, inflation, and consumer expenditures, American Economic Review 65, 843-858. 